\title{
Efeito do Estresse Térmico Agudo sobre os Níveis da Proteína e RNA Mensageiro da HSP70, em Fígado e Cérebro de Pintos de Corte de Diferentes Linhagens
}

\author{
Nelson José Laurino Dionello ${ }^{1,4}$, Jesus Aparecido Ferro ${ }^{2}$, Marcos Macari ${ }^{3}$, Fernando Rutz ${ }^{4}$, \\ Luiz Roberto Furlan ${ }^{5}$, Maria Inês Tiraboschi Ferro ${ }^{2}$
}

\begin{abstract}
RESUMO - Oitenta pintos de corte de duas linhagens, pescoço pelado ( $\mathrm{Na} / \mathrm{na})$ e Hubbard-Pettersen, entre 2 e 5 dias de idade, foram expostos a estresse térmico agudo $\left(36-37^{\circ} \mathrm{C}\right)$, durante cinco horas. Foram avaliados temperatura cloacal e peso corporal individuais ao início e final do período de estresse térmico agudo. Os pintos foram sacrificados ao final e amostras de fígado e cérebro foram coletadas e analisadas por Western Blotting e Northern Blotting, para quantificação da proteína e RNA mensageiro da Hsp70, respectivamente. Os resultados apresentaram maiores níveis protéicos de Hsp70 no tecido cerebral do que no hepático. Antes do estresse térmico, não houve diferenças de linhagens para expressão e síntese de Hsp70, em ambos os tecidos. Após o estresse térmico, as aves estressadas apresentaram maiores níveis protéicos de Hsp70, quando o tecido analisado foi o fígado (para as pescoço pelado nas idades de 4 e 5 dias), e menores níveis, em relação às controles, quando o tecido analisado foi o cérebro (para as Pescoço pelado na idade de 2 dias). $\mathrm{O}$ tamanho do transcrito de RNA mensageiro de Hsp70 foi de 2,7 kb. Os resultados do presente experimento sugerem que, para o tecido cerebral, a indução de Hsp70 ocorreu em níveis transcripcional e traducional e para o tecido hepático foi detectada apenas alteração em nível traducional, para ambas as linhagens.
\end{abstract}

Palavras-chave: estresse por calor agudo, Hsp70 hepática e cerebral, proteína e RNA mensageiro de Hsp70, Northern Blotting e Western Blotting

\section{Effect of Acute Heat Stress on Hepatic and Cerebral Messenger RNA Heat Shock Protein 70 and Heat Shock Protein 70 Level of Broiler Chicks from 2 to 5 Days Old of Different Strains}

\begin{abstract}
Eighty broiler chicks, Naked neck (Na/na) and Hubbard-Pettersen strains, were exposed to acute heat stress (36$37^{\circ} \mathrm{C}$ ), from 2 to 5 days of age, and body weight and cloacal temperature were measured in the beginning and at the end of the heat stress period $(5 \mathrm{~h})$. Birds were sacrificed at the end and liver and brain samples were collected and analyzed using Western Blotting and Northern Blotting to quantify Hsp70 levels and mRNA Hsp70 transcript, respectively. The brain tissue had higher Hsp70 level than liver tissue. Before heat stress it was not observed difference in the Hsp70 expression between strains. After heat stress in the liver it was observed in increase in the Hsp70 level (naked neck birds at 4 and 5 days), and in the brain a reduced Hsp70 level was found when compared with the control birds (Naked neck birds at 2 days). The size of the mRNA Hsp70 transcript was $2.7 \mathrm{~kb}$. The data of this experiment suggest that to the brain tissue heat stress affect Hsp70 at transcriptional and translational levels, and for hepatic tissue the effect is only at translational level, for different lines.
\end{abstract}

Key Words: acute heat stress, hepatic and brain Hsp70, protein and mRNA Hsp70, Northern Blotting and Western Blotting

\section{Introdução}

A existência de uma base genética para resistência ao calor foi comprovada por EBERHART e WASHBURN (1993b), os quais concluíram que a criação de aves com maior resistência ao calor seria a alternativa para as regiões de climas tropicais. A introdução do gene do pescoço pelado em duas populações, uma de alto e outra de baixo peso corporal, mostrou que as aves da população de alto peso corporal adquiriram resistência ao estresse por calor. Estas aves apresentaram menor consumo alimentar, o que levou à menor produção de calor interno e, conseqüente, menor risco de estresse hipertérmico. EBERHART e WASHBURN (1993a), avaliando aves de pescoço pelado e normais, encontraram correlação negativa entre a temperatura corporal basal e a variação de temperatura corporal após o

\footnotetext{
1 Doutor pelo Programa de Pós Graduação em Biotecnologia/ UFPel . E.mail: dionello@ufpel.tche.br

2 Departamento de Tecnologia. E.mail: jesus@fcav.unesp.br

${ }^{3}$ Departamento de Morfologia e Fisiologia Animal, Faculdade de Ciências Agrárias e Veterinárias, Universidade Estadual Paulista-UNESP, Jaboticabal, SP. 14870-000, Brasil. E.mail: macari@fcav.unesp.br

${ }^{4}$ Departamento de Zootecnia, Faculdade de Agronomia Eliseu Maciel, Universidade Federal de Pelotas-UFPel, Pelotas, RS. 96100-000, Brasil. E.mail: frutz@ufpel.tche.br

${ }^{5}$ Departamento de Melhoramento e Nutrição Animal, FMVZ-UNESP, Botucatu, SP.
} 
estresse térmico agudo. Já MAZZI (1998) verificou melhor desempenho das aves heterozigotas (pescoço pelado), com relação à resistência ao calor, constatando menores mortalidade e perda de peso corporal, quando submetidas ao estresse térmico agudo, em relação às homozigotas e normais. Igualmente CAHANER et al. (1993) e YAHAV et al. (1998) observaram que o desempenho de indivíduos heterozigotos $(\mathrm{Na} / \mathrm{na})$ foi superior ao dos indivíduos normais, quando expostos as altas temperaturas ambientes $\left(32^{\circ} \mathrm{C}\right)$.

A exposição ao calor foi a primeira maneira de se induzir a formação das proteínas de estresse e, por isso, elas tornaram-se conhecidas como proteínas do choque térmico (Hsps) (CRAIG, 1985; LINDQUIST e CRAIG, 1988). A aquisição de termotolerância, segundo PARSELL e LINDQUIST (1995), está relacionada com aumentos nos níveis da proteína Hsp70. A exposição dos indivíduos à hipertermia leva à resposta rápida e transitória, em níveis transcripcional e traducional, o que BURDON (1986) considerou ser o mecanismo responsável pela sobrevivência celular durante o período de estresse. Entre as Hsps, a que se apresenta em maiores níveis, a condições estressantes, é a Hsp70. MORIMOTO e FODOR (1984) verificaram a ocorrência de transcrição preferencial de RNAs mensageiros que codificam para proteínas de choque térmico, paralela ao bloqueio na transcrição de outras proteínas. Dessa forma, as Hsps atuariam como chaperones moleculares, chegando a impedir a agregação de certas proteínas durante o estresse térmico (LINDQUIST e CRAIG, 1988). A observação de determinado número de genes ativos das Hsps, tanto nos indivíduos controles quanto nos estressados, foi realizada por BALER et al. (1992), detectando as formas constitutiva e induzida, dessas proteínas.

O mecanismo molecular envolvido na aclimatação e tolerância ao calor nas aves não tem sido perfeitamente entendido. Diversos autores encontraram níveis protéicos ou RNA mensageiro de Hsp70, em células de aves in vitro (MILLER e QURESHI, 1992a e b; MORIMOTO et al., 1986) e em tecidos de aves in vivo (WANG e EDENS 1993 e 1994; GABRIEL et al., 1996; GIVISIEZ, 1997 e MAZZI, 1998). Estudos realizados por WANG e EDENS (1994) e GABRIEL et al. (1996) demonstraram aumento nos níveis desta proteína e em seu RNA mensageiro em diferentes tecidos de aves expostas a altas temperaturas. YAHAV et al. (1997) comprovaram que o condicionamento $\left(36^{\circ} \mathrm{C}\right)$ dos pintinhos até a idade de 5 dias melhorou a termotolerância aos 42 dias de vida, sendo os níveis de Hsp70 no coração e pulmões menores que nas aves controles.

O objetivo do presente trabalho foi avaliar os efeitos do estresse térmico agudo $\left(36 \pm 1{ }^{\circ} \mathrm{C}\right)$ aplicado em pintos de corte, de uma linhagem comercial (Hubbard-Pettersen) comparada ao genótipo Pescoço pelado $(\mathrm{Na} / \mathrm{na})$, sobre a síntese e expressão da proteína de $70 \mathrm{kD}$ (Hsp70), na idade de 2 a 5 dias.

\section{Material e Métodos}

\section{Estresse térmico}

Quarenta pintos de duas linhagens: pescoço pelado ( $\mathrm{Na} / \mathrm{na}$ ) e Hubbard-Pettersen, do $2^{\circ}$ ao $5^{\circ}$ dia de idade, foram estressados a $36 \pm 1^{\circ} \mathrm{C}$ durante 5 horas/dia e os outros quarenta pintos das mesmas linhagens foram mantidos em condições de termoneutralidade $\left(32^{\circ} \mathrm{C}\right)$. A temperatura cloacal foi avaliada ao início e final do período experimental, pormeio de uma sonda introduzida $5 \mathrm{~cm}$ na cloaca (termistor) e acoplada a um teletermômetro (Yellow Spring Instruments Co., Ohio). Todos os pintos foram pesados ao início e final do período de estresse, quando foram mantidos sem água e ração. Em cada dia, cinco pintos, escolhidos ao acaso, de cada linhagem e submetidos ou não ao calor, foram sacrificados ao final do período de estresse, sendo colhidas amostras de fígado e cérebro. Essas amostras foram utilizadas para determinação da quantidade de proteína Hsp70 (fígado e cérebro) e RNA mensageiro de Hsp70 (cérebro). As variáveis obtidas foram analisadas pelo Estat - Sistema para Análises Estatísticas do Departamento de Ciências Exatas da FCAV-UNESP. Para análise de variância foi utilizado um arranjo fatorial $2 \times 2 \times 4$, para os efeitos de linhagens (Pescoço pelado e Hubbard-Pettersen), estresse (estressados e controles) e idade (2, 3, 4 e 5 dias).

O seguinte modelo matemático foi usado:

$\mathrm{Y}_{\mathrm{ijkl}}=\mathrm{m}+\mathrm{l}_{\mathrm{i}}+\mathrm{s}_{\mathrm{j}}+\mathrm{d}_{\mathrm{k}}+1 \mathrm{~s}_{\mathrm{ij}}+\mathrm{ld}_{\mathrm{ik}}+\mathrm{sd}_{\mathrm{jk}}+1 \mathrm{sd} \mathrm{ijk}_{\mathrm{ijkl}}$, em que: $Y_{i j k l}=$ observação 1 , pertencente à linhagem $i$, do tratamento $\mathrm{j}$, no dia $\mathrm{k} ; \mathrm{l}_{\mathrm{i}}=$ efeito da linhagem $\mathrm{i}$ $(i=1,2) ; s_{j}=$ efeito do estresse $j,(j=1,2) ; d_{k}=$ efeito da idade em dias $\mathrm{k},(\mathrm{k}=2,3,4,5) ; 1 \mathrm{~s}_{\mathrm{ij}}=$ efeito da interação linhagem $x$ estresse; $l_{\mathrm{ik}}=$ efeito da interação linhagem $\mathrm{x}$ idade em dias; $\mathrm{sd}_{\mathrm{jk}}=$ efeito da interação estresse $\mathrm{x}$ idade em dias; $1 \mathrm{sd}_{\mathrm{ijk}}=$ efeito da interação linhagem $\mathrm{x}$ estresse $\mathrm{x}$ idade em dias; $\mathrm{e}_{\mathrm{ijkl}}=$ erro experimental, associado a cada observação.

\section{Análise de Western Blotting}

Meio grama de fígado ou cérebro das aves foi homogeneizado, com homogeneizador ultra turrax, 
em $5 \mathrm{~mL}$ de tampão de lise (20mM tris pH 7,5, 0,75 M cloreto de sódio, $2 \mathrm{mM}$ 2-b-mercaptoetanol) e centrifugado a $30.000 \times \mathrm{xg}$ por 30 minutos a $4^{\circ} \mathrm{C}$. A concentração de proteína do sobrenadante foi quantificada pelo método de HARTREE(1972), usando soro albumina bovina como padrão. Trinta microgramas de proteína total foram aplicados e separados em gel de 9\% poliacrilamida contendo SDS (LAEMMLI, 1970), usando sistema da Bio-Rad (Mini Protean II). Os géis foram corados com Coomassie blue, segundo método proposto por MORRISSEY (1981), e transferidos para membranas de nitrocelulose, segundo procedimento proposto por TOWBIN et al. (1979). Logo após, as membranas foram corada em Ponceau $\mathrm{S}(0,5 \%$ em ácido acético $1 \%$ ) para verificação da eficiência de transferência. Após a remoção do Ponceau S por lavagem em água deionizada, as membranas foram incubadas em $10 \mathrm{~mL}$ de TBS-leite em pó gelado $(10 \mathrm{mM}$ tris, $\mathrm{pH} 8,0 ; 150 \mathrm{mM}$ cloreto de sódio; $5 \%$ leite em pó desnatado e $0,02 \%$ Tween-20) por 1 hora para bloqueamento de sítios de ligação não específicos. As membranas foram então incubadas com $10 \mathrm{~mL}$ de TBSleite em pó gelado contendo anticorpo monoclonal (Sigma Chemical Co., St Louis, MO) anti Hsp70 na diluição de 1:1000. Após a incubação, as membranas foram lavadas quatro vezes (cinco minutos cada) com $10 \mathrm{~mL}$ de TBST gelado (10 mM tris, $\mathrm{pH} 8,0 ; 150 \mathrm{mM}$ cloreto de sódio e $0,05 \%$ Tween-20) e 1 vez (10 minutos) com TBS gelado. Adicionou-se o anticorpo secundário anti $\operatorname{IgG}$ de camundongo conjugado à fosfatase alcalina (Sigma Chemical Co., St Louis, MO) por 1 hora. Após lavagens com TBST e TBS gelada, foi desenvolvida a reação de cor, utilizando os substratos cromogênicos $(0,3 \mathrm{mg} / \mathrm{mL}$ NBT (nitrobluetetrazolium) e $0,15 \mathrm{mg} / \mathrm{mL} \mathrm{BCIP} \mathrm{(5-bromo-}$ 4-cloro-3-indolil fosfato)) em tampão contendo 100 $\mathrm{mM}$ tris, $\mathrm{pH} 9,5,100 \mathrm{mM}$ cloreto de sódio e $5 \mathrm{mM}$ cloreto de magnésio.

\section{Quantificação das amostras de proteina total}

Os sinais obtidos para análise de Western Blotting foram quantificados por meio de um densitômetro (Model CS-9000, Shimadzu, Japan) e determinada a relação de área entre a área de cada amostra e a área da amostra de referência. Utilizando uma curva padrão elaborada para a relação de área entre áreas de diferentes concentrações da proteína Hsp70 em ng por $\mathrm{mL}$, foi possível obter-se a quantidade de Hsp70 em cada amostra individual de fígado ou cérebro em ng de Hsp70 por mg de proteína total.

\section{Análise de Northern Blotting}

O RNA total foi obtido de 0,5 grama de fígado ou cérebro de acordo com o método descrito por CHOMCZYNSKI e SACCHI (1987). Vinte microgramas de RNA total foram desnaturados com formaldeido (SAMBROOK et al., 1989), separados por eletroforese em gel de agarose de 1,2\% - 2,2 M formaldeido e transferidos (SOUTHERN, 1975) para membranas de nylon usando 10X SSPE (20X SSPE= $3 \mathrm{M} \mathrm{NaCl} ; 0,2 \mathrm{M} \mathrm{NaH}_{2} \mathrm{PO}_{4} \cdot \mathrm{H}_{2} \mathrm{O} ; 0,02 \mathrm{M}$ EDTA, $\mathrm{pH}$ $7,4)$. Antes da transferência, foi observada a integridade do RNA no gel de agarose em um transiluminador (Foto/Prep II, Fotodyne Incorporated, New Berlin, WI). A fixação do RNA ocorreu pela colocação das membranas em um transiluminador (CL-1000 Ultraviolet Crosslinker). Os sinais das moléculas específicas de RNA mensageiro de Hsp70 foram verificados usando uma sonda de DNA complementar de Hsp70 de galinha marcada com $\left[\mathrm{a}^{32} \mathrm{P}\right]$ dATP e $\left[\mathrm{a}^{32} \mathrm{P}\right]$ dCTP, conforme o método de "random primed DNA" de FEINBERG e VOGELSTEIN (1983), usando um kit da Boehringer (Boehringer Mannheim Gmbh, Mannheim, Germany). As membranas foram préhibridizadas durante 2 horas com 5x SSPE, 50\% formamida, $5 \mathrm{x}$ Denhardt's reagent $(1 \mathrm{xDenhardt} \mathrm{s}=$ $200 \mathrm{mM}$ Ficoll, $200 \mathrm{mg} / \mathrm{mL}$ polyvinylpyrrolidina e 20 $\mathrm{mg} / \mathrm{mL}$ BSA), 0,1\% SDS e $100 \mathrm{mg} / \mathrm{mL}$ de DNA de esperma de salmão desnaturado, $\mathrm{a} 42^{\circ} \mathrm{C}$. A hibridização foi conduzida durante a noite, a $42^{\circ} \mathrm{C}$, e, logo após, as membranas foram lavadas em condições de alta estringência, 1 vez (30 minutos) com "Wash I" (2x SSPE; $0,1 \%$ SDS) a $42^{\circ} \mathrm{C}, 2$ vezes ( 30 minutos) a $65^{\circ} \mathrm{C}$ com "Wash II" (1x SSPE; 0,1\% SDS) e 2 vezes (30 minutos) a $65^{\circ} \mathrm{C}$ com "Wash III" ( $0,1 \%$ SSPE; $0,1 \%$ $\mathrm{SDS}$ ), sendo expostas a filme de raio $\mathrm{X}$, em chassis com intensificador a $-80^{\circ} \mathrm{C}$, durante 6 dias. Após a exposição, as membranas foram lavadas para retirada da sonda de Hsp 70 e re-hibridizadas com sonda de $28 \mathrm{~S}$, usando-se o mesmo protocolo acima descrito. A exposição a filme de raio $X$ foi por um período de 60 minutos. Os sinais obtidos nas análises de Northern Blotting foram quantificados por um densitômetro (Model CS-9000, Shimadzu, Japan).

\section{Resultados e Discussão}

Os valores dos níveis protéicos de Hsp70 observados na fração solúvel (sobrenadante) das amostras de fígado estão apresentados na Tabela 1. Foram 
Tabela 1 - Níveis médios e erro padrão de Hsp70 (ng Hsp70/mg proteína total) na fração solúvel de tecido hepático por linhagens, estresse e idades, para pintos de corte

Table 1 - Average Hsp70 levels (ng Hsp70/mg total protein) in hepatic tissue for strains, stress and age, from broiler chickens

\begin{tabular}{|c|c|c|c|c|c|}
\hline \multirow[t]{2}{*}{$\begin{array}{l}\text { Linhagem } \\
\text { Strain }\end{array}$} & \multirow[t]{2}{*}{$\begin{array}{l}\text { Estresse } \\
\text { Stress }\end{array}$} & \multicolumn{4}{|c|}{$\begin{array}{l}\text { Idade (dias) } \\
\text { Age (days) }\end{array}$} \\
\hline & & 2 & 3 & 4 & 5 \\
\hline & & \multicolumn{4}{|c|}{$\begin{array}{l}\text { Efeito do estresse } \\
\text { Stress effect }\end{array}$} \\
\hline Pescoço pelado & Estressados & $6,9 \pm 0,4^{\mathrm{a}}$ & $4,5 \pm 0,4^{\mathrm{a}}$ & $8,5 \pm 0,5^{\mathrm{a}}$ & $8,7 \pm 0,5^{\mathrm{a}}$ \\
\hline Naked neck & Stressed & & & & \\
\hline $\begin{array}{l}\text { Pescoço pelado } \\
\text { Naked neck }\end{array}$ & $\begin{array}{l}\text { Controle } \\
\text { Control }\end{array}$ & $7,0 \pm 0,7^{\mathrm{a}}$ & $4,3 \pm 0,3^{\mathrm{a}}$ & $5,6 \pm 0,8^{b}$ & $5,1 \pm 0,8^{b}$ \\
\hline Hubbard-Pettersen & $\begin{array}{l}\text { estressados } \\
\text { Stressed }\end{array}$ & $6,4 \pm 0,5^{\mathrm{a}}$ & $6,9 \pm 0,7^{\mathrm{a}}$ & $6,6 \pm 1,0^{\mathrm{a}}$ & $5,8 \pm 0,3^{\mathrm{a}}$ \\
\hline \multirow[t]{2}{*}{ Hubbard-Pettersen } & $\begin{array}{l}\text { Controle } \\
\text { Control }\end{array}$ & $6,2 \pm 0,5^{\mathrm{a}}$ & $7,0 \pm 0,8^{\mathrm{a}}$ & $4,6 \pm 0,4^{\mathrm{a}}$ & $6,9 \pm 0,5^{\mathrm{a}}$ \\
\hline & & \multicolumn{4}{|c|}{$\begin{array}{l}\text { Efeito da linhagem } \\
\text { Strain effect }\end{array}$} \\
\hline $\begin{array}{l}\text { Pescoço pelado } \\
\text { Naked neck }\end{array}$ & $\begin{array}{l}\text { Estressados } \\
\text { Stressed }\end{array}$ & $6,9 \pm 0,4^{\mathrm{a}}$ & $4,5 \pm 0,4^{b}$ & $8,5 \pm 0,5^{\mathrm{a}}$ & $8,7 \pm 0,5^{\mathrm{a}}$ \\
\hline Hubbard-Pettersen & $\begin{array}{l}\text { Estressados } \\
\text { Stressed }\end{array}$ & $6,4 \pm 0,5^{\mathrm{a}}$ & $6,9 \pm 0,7^{\mathrm{a}}$ & $6,6 \pm 1,0^{\mathrm{a}}$ & $5,8 \pm 0,3^{b}$ \\
\hline $\begin{array}{l}\text { Pescoço pelado } \\
\text { Naked neck }\end{array}$ & $\begin{array}{l}\text { Controle } \\
\text { Control }\end{array}$ & $7,0 \pm 0,7^{\mathrm{a}}$ & $4,3 \pm 0,3^{b}$ & $5,6 \pm 0,8^{b}$ & $5,1 \pm 0,8^{\mathrm{b}}$ \\
\hline Hubbard-Pettersen & $\begin{array}{l}\text { Controle } \\
\text { Control }\end{array}$ & $6,2 \pm 0,5^{\mathrm{a}}$ & $7,0 \pm 0,8^{a}$ & $4,6 \pm 0,4^{\mathrm{a}}$ & $6,9 \pm 0,5^{\mathrm{a}}$ \\
\hline
\end{tabular}

Médias, na coluna, seguidas de letras diferentes diferem significativamente pelo teste Tukey $(P<0,05)$.

Means, within a column, followed by different letters are significantly different by Tukey test $(P<.05)$.

encontradas diferenças estatísticas para os efeitos de linhagens e estresse, dentro das idades avaliadas. Para o efeito de estresse, os resultados mostraram que os pintos Pescoço pelado estressados apresentaram maiores níveis de Hsp70 $(\mathrm{P}<0,05)$ no fígado, nas idades de 4 e 5 dias, do que os pescoço pelado controles. Entre os pintos Hubbard-Pettersen, estressados e controles, não houve diferença entre os níveis de Hsp70 no fígado, nas diferentes idades. Com relação à linhagem, constatou-se diferença $(\mathrm{P}<0,05)$ entre os níveis de Hsp70 hepático para os pintos estressados nas idades de 3 e 5 dias, sendo que os da linhagem HubbardPettersen apresentaram maiores níveis de Hsp70 no fígado $(6,9>4,5 \mathrm{ng}$ de $\mathrm{Hsp} 70 / \mathrm{mg}$ de proteína total) na idade de 3 dias do que os pescoço pelado, enquanto o inverso correu na idade de 5 dias. Este resultado ocorrido na idade de 3 dias está de acordo com os resultados obtidos por EDENS etal. (1992), GABRIEL et al. (1995) e MAZZI (1998), os quais verificaram que aves de linhagens selecionadas apresentaram maiores níveis de Hsp70 no fígado, quando estressadas.

Como em aves a Hsp70 é tanto constitutiva quanto induzida, igualmente em pintos controles Hubbard-Pettersen houve maior síntese de Hsp70 na idade de 3 dias $(\mathrm{P}<0,05)$.

$\mathrm{Na}$ Tabela 2 são apresentados os resultados dos níveis protéicos de Hsp70 observados na fração solúvel das amostras de cérebro. Observou-se que os pintos controles Pescoço pelado, na idade de 2 dias, apresentaram maiores níveis $(\mathrm{P}<0,05)$ de Hsp70 (10,6>7,8 ng Hsp70/mg de proteína total). Com relação à linhagem, houve na idade de 2 dias diferença significativa entre os controles, com os pintos pescoço pelado apresentando maior nível de Hsp70.

Comparando-se os resultados obtidos em ambos tecidos, pode-se verificar que os mecanismos de resposta dos dois tecidos estudados agiram de forma oposta. Enquanto ao se analisar o tecido hepático, os pintos estressados pescoço pelado nas idades de 4 e 5 dias apresentaram maiores níveis de Hsp70 $(\mathrm{P}<0,05)$, nas amostras colhidas no cérebro, os indivíduos controles pescoço pelado na idade de 2 dias apresentaram maiores níveis de Hsp70 $(\mathrm{P}<0,05)$. Com relação aos tecidos do cérebro, SCHMIDT-NIELSEN (1995) relatou que alguns animais apresentam mecanismos que não permitem a este órgão um aumento de temperatura, mantendo-se o mesmo, inclusive com temperatura de 2 a $3^{\circ} \mathrm{C}$ abaixo da temperatura corporal. 
Tabela 2 - Níveis médios ( \pm EPM) de Hsp70 (ng Hsp70/mg proteína total) na fração solúvel de tecido cerebral por linhagens, estresse e idades, para pintos de corte

Table 2 - Average Hsp 70 levels (ng Hsp70/mg total protein) in cerebral tissue for strains, stress and age, from broiler chickens

\begin{tabular}{|c|c|c|c|c|c|}
\hline \multirow[t]{2}{*}{$\begin{array}{l}\text { Linhagem } \\
\text { Strain }\end{array}$} & \multirow[t]{2}{*}{$\begin{array}{l}\text { Estresse } \\
\text { Stress }\end{array}$} & \multicolumn{4}{|c|}{$\begin{array}{l}\text { Idade (dias) } \\
\text { Age (days) }\end{array}$} \\
\hline & & 2 & 3 & 4 & 5 \\
\hline & & \multicolumn{4}{|c|}{$\begin{array}{l}\text { Efeito do estresse } \\
\text { Stress effect }\end{array}$} \\
\hline Pescoço pelado & Estressados & $7,8 \pm 0,3^{\mathrm{b}}$ & $9,6 \pm 1,3^{\mathrm{a}}$ & $7,6 \pm 0,5^{\mathrm{a}}$ & $5,8 \pm 0,6^{\mathrm{a}}$ \\
\hline Naked neck & Stressed & & & & \\
\hline Pescoço pelado & Controle & $10,6 \pm 0,7^{\mathrm{a}}$ & $12,3 \pm 0,8^{\mathrm{a}}$ & $7,3 \pm 0,9^{\mathrm{a}}$ & $7,4 \pm 0,5^{\mathrm{a}}$ \\
\hline $\begin{array}{l}\text { Naked neck } \\
\text { Hubbard-Pettersen }\end{array}$ & $\begin{array}{l}\text { Control } \\
\text { estressados } \\
\text { Stressed }\end{array}$ & $7,5 \pm 0,2^{\mathrm{a}}$ & $7,5 \pm 0,9^{\mathrm{a}}$ & $7,2 \pm 1,4^{\mathrm{a}}$ & $7,9 \pm 1,6^{\mathrm{a}}$ \\
\hline \multirow[t]{2}{*}{ Hubbard-Pettersen } & $\begin{array}{l}\text { Controle } \\
\text { Control }\end{array}$ & $6,7 \pm 0,4^{\mathrm{a}}$ & $10,3 \pm 0,9^{\mathrm{a}}$ & $7,4 \pm 1,1^{\mathrm{a}}$ & $7,7 \pm 1,2^{\mathrm{a}}$ \\
\hline & & \multicolumn{4}{|c|}{$\begin{array}{l}\text { Efeito da linhagem } \\
\text { Strain effect }\end{array}$} \\
\hline $\begin{array}{l}\text { Pescoço pelado } \\
\text { Naked neck }\end{array}$ & $\begin{array}{l}\text { Estressados } \\
\text { Stressed }\end{array}$ & $7,7 \pm 0,3^{\mathrm{a}}$ & $9,6 \pm 1,4^{\mathrm{a}}$ & $7,6 \pm 0,5^{\mathrm{a}}$ & $5,8 \pm 0,6^{\mathrm{a}}$ \\
\hline Hubbard-Pettersen & $\begin{array}{l}\text { Estressados } \\
\text { Stressed }\end{array}$ & $7,5 \pm 0,2^{\mathrm{a}}$ & $7,5 \pm 0,9^{\mathrm{a}}$ & $7,2 \pm 1,4^{\mathrm{a}}$ & $7,9 \pm 1,6^{\mathrm{a}}$ \\
\hline $\begin{array}{l}\text { Pescoço pelado } \\
\text { Naked neck }\end{array}$ & $\begin{array}{l}\text { Controle } \\
\text { Control }\end{array}$ & $10,6 \pm 0,7^{\mathrm{a}}$ & $12,3 \pm 0,8^{\mathrm{a}}$ & $7,3 \pm 0,9^{\mathrm{a}}$ & $7,4 \pm 0,5^{\mathrm{a}}$ \\
\hline Hubbard-Pettersen & $\begin{array}{l}\text { Controle } \\
\text { Control }\end{array}$ & $6,7 \pm 0,4^{\mathrm{b}}$ & $10,3 \pm 0,9^{\mathrm{a}}$ & $7,4 \pm 1,1^{\mathrm{a}}$ & $7,7 \pm 1,2^{\mathrm{a}}$ \\
\hline
\end{tabular}

Médias, na coluna, seguidas de letras diferentes diferem significativamente pelo teste Tukey $(P<0,05)$.

Means, within a column, followed by different letters are significantly different by Tukey test $(P<.05)$.

Na Figura 1 é apresentada a autorradiografia do Northern Blotting, mostrando o transcrito de RNA mensageiro de Hsp70 no tecido cerebral, com tamanho de $2,7 \mathrm{~kb}$. A presença do transcrito pode ser notada nesse tecido, sendo que isto ocorreu em ambas linhagens, tanto nas aves estressadas quanto nas controles, em todos os dias. Este resultado corrobora as observações de YAHAV et al. (1997), que, analisando amostras de tecidos de pulmões de frangos de corte, detectaram a hibridização do RNA total, em indivíduos estressados ou não. $O$ tamanho do transcrito de 2,7 kb (Figura 1) foi semelhante àqueles obtidos em trabalhos realizados por MORIMOTO et al. (1986) e GABRIEL (1996).

Na Tabela 3 estão os resultados dos níveis de RNA mensageiro do tecido cerebral. Não houve efeito do estresse sobre os níveis de RNA mensageiro de pintos pescoço pelado. Entretanto, os pintos pescoço pelado controles apresentaram maiores valores absolutos para o RNA mensageiro nas idade de 2 e 3 dias e menor na idade de 5 dias, em relação aos estressados. Já para os pintos HubbardPettersen, observou-se diferença significativa nas idades de 2 e 5 dias, ocorrendo maiores valores
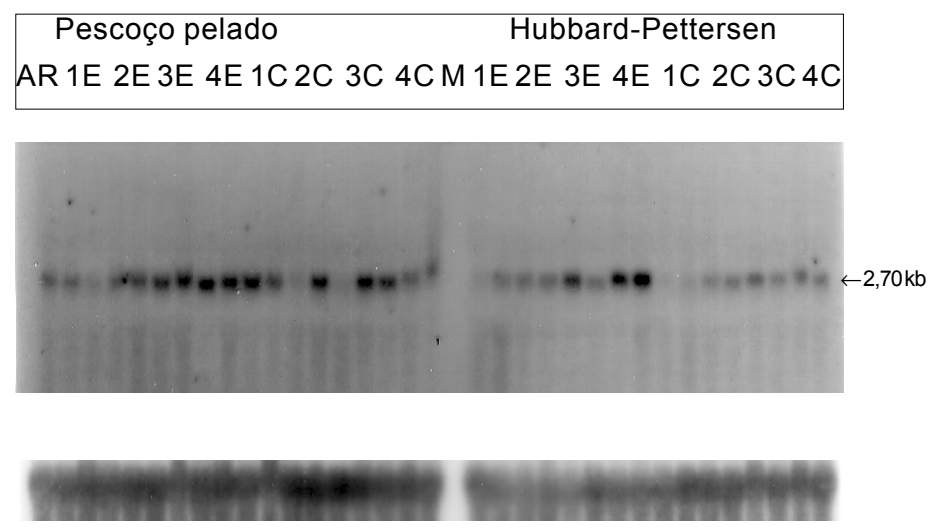

Figura 1 - (A) - Autorradiografia do Northern Blotting obtido a partir de $20 \mathrm{mg}$ de RNA total de tecido de cérebro de pintos linhagens Pescoço pelado e Hubbard-Pettersen, estressados e controles, nas idades de 2, 3, 4 e 5 dias. AR - amostra de referência, 1E - estressado da idade de 2 dias, $1 C$ - não estressado da idade de 2 dias, M - marcador RNA ribossomal 23S e 16S. (B) - Autorradiografia do Northern Blotting usando RNA ribossomal $28 \mathrm{~S}$ sobre a mesma membrana.

Figure 1 - (A) - Northern blot analysis from $20 \mathrm{mg}$ of total RNA in cerebral tissue isolated from control and heat stressed broiler chickens (Naked neck and Hubbard-Pettersen), from 2 to 5 days old. AR - reference sample, $1 E$ - stressed 2 days, $1 C$ - control 2 days, $M$ - RNA marker. (B) Northern blot with ribosomal $28 S$ RNA. 
$(\mathrm{P}<0,05)$ de RNA mensageiro para os pintos controles aos 2 dias de idade e para os estressados aos 5 dias de idade. Com relação ao efeito de linhagem, observou-se apenas diferença $(\mathrm{P}<0,05)$ na idade de 2 dias, quando os pintos controles Hubbard-Pettersen apresentaram maior quantidade de RNA mensageiro que os pescoço pelado controles.

Para o tecido hepático, onde não apareceram os transcritos nas amostras analisadas, estes resultados corroboram os de YAHAV et al. (1997), obtidos em estudos realizados também com este tecido. Este fato pode ter ocorrido em função do tempo de exposição, pois, segundo SKIDMORE et al. (1995), o nível máximo de Hsp70 induzida é variável entre os tecidos colhidos e pode ocorrer algumas horas após a exposição dos indivíduos aos estressantes. A idade das aves também pode ser importante, sendo os pintos mais resistentes ao estresse térmico agudo que as aves adultas (MACARI et al., 1994) e, assim, maiores temperaturas seriam necessárias para que houvesse a expressão de RNA mensageiro de Hsp70, como foi evidenciado em resultados de pesquisas de GABRIEL (1996), que, trabalhando com amostras de fígado de frangos de corte, mostraram sinais não tão claros na hibridização (autorradiografia) para o primeiro dia de vida das aves em relação as hibridizações obtidas nas idades de $21 \mathrm{e}$ 42 dias. Outro fator importante pode ser a temperatura utilizada no momento do estresse térmico agudo, que pode ter sido responsável pela pequena indução de Hsp70 e pelo fraco sinal obtido nas autorradiografias, não permitindo sua leitura pelo densitômetro.

Alguns autores (YAHAV et al., 1997) sugerem que a indução da síntese de Hsps em tecidos corporais está diretamente correlacionada com a extensão do período de hipertermia, o que permite inferir que o tempo de exposição ao estresse térmico pode não ter sido suficiente para indução das Hsps ou que a resposta ao estresse térmico pode ter sido transitória.

Provavelmente, de acordo com os resultados obtidos para os níveis protéicos de Hsp70, em que maior quantidade desta proteína foi encontrada no tecido cerebral em relação ao tecido hepático, a quantidade de RNA mensageiro apresentada pelo tecido hepático deve ser menor do que a quantidade apresentada pelo tecido cerebral. Igualmente, sabe-se de que apenas 5\% do RNA total é RNA mensageiro e, segundo THEODORAKIS et al. (1988), em reticulócitos de galinha, ao aplicar-se o choque

Tabela 3 - Níveis médios ( \pm EPM) de RNA mensageiro de Hsp70 (unidades arbitrárias) em tecido cerebral por linhagens, estresse e idades, para pintos de corte

Table 3 - Average levels (arbiter units) of messenger RNA Hsp 70 in cerebral tissue for strains, stress and age, from broiler chickens

\begin{tabular}{|c|c|c|c|c|c|}
\hline \multirow[t]{2}{*}{$\begin{array}{l}\text { Linhagem } \\
\text { Strain }\end{array}$} & \multirow[t]{2}{*}{$\begin{array}{l}\text { Estresse } \\
\text { Stress }\end{array}$} & \multicolumn{4}{|c|}{$\begin{array}{c}\text { Idade (dias) } \\
\text { Age (days) }\end{array}$} \\
\hline & & 2 & 3 & 4 & 5 \\
\hline & & \multicolumn{4}{|c|}{$\begin{array}{l}\text { Efeito do estresse } \\
\text { Stress effect }\end{array}$} \\
\hline Pescoço pelado & Estressados & $1,4 \pm 0,1^{\mathrm{a}}$ & $1,8 \pm 0,6 \mathrm{a}^{\mathrm{a}}$ & $1,3 \pm 0,3^{\mathrm{a}}$ & $2,9 \pm 0,8^{\mathrm{a}}$ \\
\hline Naked neck & Stressed & & & & \\
\hline Pescoço pelado & Controle & $1,8 \pm 0,4^{\mathrm{a}}$ & $2,6 \pm 0,4^{\mathrm{a}}$ & $1,4 \pm 0,2^{\mathrm{a}}$ & $1,5 \pm 0,6^{\mathrm{a}}$ \\
\hline Naked neck & Control & & & & \\
\hline Hubbard-Pettersen & $\begin{array}{l}\text { estressados } \\
\text { Stressed }\end{array}$ & $2,3 \pm 0,7^{b}$ & $1,2 \pm 0,2^{\mathrm{a}}$ & $1,9 \pm 0,4^{\mathrm{a}}$ & $2,6 \pm 0,4^{\mathrm{a}}$ \\
\hline \multirow[t]{2}{*}{ Hubbard-Pettersen } & $\begin{array}{l}\text { Controle } \\
\text { Control }\end{array}$ & $4,3 \pm 0,0^{\mathrm{a}}$ & $1,5 \pm 0,6^{\mathrm{a}}$ & $1,4 \pm 0,1^{\mathrm{a}}$ & $1,4 \pm 0,2^{b}$ \\
\hline & & \multicolumn{4}{|c|}{$\begin{array}{l}\text { Efeito da linhagem } \\
\text { Strain effect }\end{array}$} \\
\hline Pescoço pelado & Estressados & $1,4 \pm 0,1^{\mathrm{a}}$ & $1,8 \pm 0,6^{\mathrm{a}}$ & $1,3 \pm 0,3^{\mathrm{a}}$ & $2,9 \pm 0,8^{\mathrm{a}}$ \\
\hline Naked neck & Stressed & & & & \\
\hline Hubbard-Pettersen & $\begin{array}{l}\text { Estressados } \\
\text { Stressed }\end{array}$ & $2,3 \pm 0,7^{\mathrm{a}}$ & $1,2 \pm 0,2^{\mathrm{a}}$ & $1,9 \pm 0,4^{\mathrm{a}}$ & $2,6 \pm 0,4^{\mathrm{a}}$ \\
\hline Pescoço pelado & Controle & $1,8 \pm 0,4^{b}$ & $2,6 \pm 0,4^{\mathrm{a}}$ & $1,4 \pm 0,2^{\mathrm{a}}$ & $1,5 \pm 0,6^{\mathrm{a}}$ \\
\hline Naked neck & Control & & & & \\
\hline Hubbard-Pettersen & $\begin{array}{l}\text { Controle } \\
\text { Control }\end{array}$ & $4,3 \pm 0,0^{\mathrm{a}}$ & $1,5 \pm 0,6^{\mathrm{a}}$ & $1,4 \pm 0,1^{\mathrm{a}}$ & $1,4 \pm 0,2^{\mathrm{a}}$ \\
\hline
\end{tabular}

Médias, na coluna, seguidas de letras diferentes diferem significativamente pelo teste Tukey $(\mathrm{P}<0,05)$.

Means, within a column, followed by different letters are significantly different by Tukey test $(P<.05)$.

Rev. bras. zootec., 30(5):1506-1513, 2001 
térmico, os níveis de RNA mensageiro aumentaram 2 vezes, enquanto a síntese protéica chega a ser aumentada em 10 vezes. Nos indivíduos estressados, os níveis de RNA mensageiro diminuíram, em valores absolutos, com a idade, concordando com resultados obtidos por WANG e EDENS (1994) e HEYDARI et al. (1993), os quais verificaram aumento em aves, com subseqüente queda e, em ratos, diminuição com a idade, nos níveis de RNA mensageiro e protéicos de Hsp70, respectivamente.

\section{Conclusões}

As linhagens apresentaram semelhança quanto aos níveis protéicos e de RNA mensageiro de Hsp70.

A indução da Hsp70 em resposta ao estresse térmico ocorreu tanto em nível transcripcional quanto em nível de tradução, para o tecido cerebral e somente em nível traducional para o tecido hepático.

\section{Agradecimento}

À Fundação de Amparo à Pesquisa do Estado de São Paulo (FAPESP) e a Coordenação de Aperfeiçoamento de Pessoal de Nível Superior (PICD/CAPES), pelo suporte financeiro.

\section{Referências Bibliográficas}

BALER, R., WELCH, W.J., VOELLMY, R. 1992. Heat shock regulation by nascent polypeptides and denatured proteins: Hsp70 as a potential autoregulatory factor. J. Cell. Biol., 117(6):1151-1159.

BURDON, R.H. 1986. Heat shock and the heat shock proteins. Biochemistry J., 240(2):313-324.

CAHANER, A., BEEB, N., GUTMAN, M. 1993. Effects of the plumage-reducing naked neck $(\mathrm{Na})$ gene on the performance of fast-growing broilers at normal and high ambient temperatures. Poult. Sci., 72(5):767-775.

CHOMCZYNSKI, P., SACCHI, N. 1987. Single-step method of RNA isolation by acid guanidinium thiiocyanate-phenolchloroform extraction. Anal. Biochem., 162(1):156-159.

CRAIG, E.A. 1985. The heat shock response. Crit. Rev. Biochem., 18(3):239-280.

EDENS, F.W., HILL, C.H., WANG, S. 1992. Heat-shock protein response in phosphorous-deficient heat-stressed broiler chickens. Comp. Biochem. Physiol., 103b(4):827-831.

EBERHART, D.E., WASHBURN, K.W. 1993a. Variation in body temperature response of naked neck and normally feathered chickens to heat stress. Poult. Sci., 72(8):1385-1390.

EBERHART, D.E., WASHBURN, K.W. 1993b. Assessing the effects of the naked neck gene on chronic heat stress resistance in two genetic populations. Poult. Sci., 72(8):1391-1399.

FEINBERG, A.P., VOGELSTEIN, B. 1983. A technique for radiolabeling DNA restriction endonuclease fragments to high specific activity. Anal. Biochem., 119B(3):421-429.

GABRIEL, J.E. Efeitos do nível energético da ração e do estresse térmico na expressão da proteína de choque térmico Hsp 70 e nos níveis de seu RNA mensageiro no fígado de frangos de corte em diferentes estágios de desenvolvimento. Jaboticabal, SP: FCAV/UNESP- 1996. 84p. Dissertação (Mestrado em Zootecnia) - Universidade Estadual Paulista, 1996.

GABRIEL, J.E., GUERREIRO, E.N., SILVA, M.M. et al. Padrão de expressão da proteína de choque térmico de $70 \mathrm{kDa}$ (Hsp70) em aves selecionadas e não selecionadas submetidas a um estresse calórico agudo. In: CONFERÊNCIA APINCO DE CIÊNCIA E TECNOLOGIA AVÍCOLAS, Curitiba, 1995. Anais... Campinas: FACTA, 1995. p.303-304.

GABRIEL, J.E., FERRO, J.A., STEFANI, R.M.P. et al. 1996. Effect of acute heat stress on heat shock protein 70 messenger RNA and on heat shock protein expression in the liver of broilers. Br. Poult. Sci., 37(2):443-449.

GIVISIEZ, P.E.N. Mecanismos hormonais e moleculares da termotolerância em frangos de corte. Jaboticabal, SP: FCAVUNESP, 1997. 77p. Dissertação (Mestrado em Zootecnia) Universidade Estadual Paulista, 1997.

HARTREE, E.F. 1972. Determination of protein: a modification of the Lowry method that gives a linear photometric response. Anal. Biochem., 48(2):422-427.

HEYDARI, A.R., WU, B., TAKAHASHI, R. et al. 1993. Expression of heat shock protein 70 is altered by age and diet at the level of transcription. Mol. Cel. Biol., 13(5):2909-2018.

LAEMMLI, U.K. 1970. Cleavage of structural proteins during the assembly of the head of bacteriophage T4. Nature, 227:680-685.

LINDQUIST, S., CRAIG, E.A. 1988. The heat-shock proteins. Ann. Rev. of Gen., 22(3):631-677.

MACARI, M., FURLAN, R.L., GONZALEZ, E. 1994. Fisiologia aviária aplicada a frangos de corte. Jaboticabal: FUNEP/UNESP. 296p.

MAZZI, C.M. Análise da expressão da proteina de estresse Hsp70 em frangos de corte portadores do gene "naked neck"(pescoço pelado) submetidos a estresse térmico gradativo. Jaboticabal, SP: FCAV-UNESP, 1998. 60p. Dissertação (Mestrado em Agronomia) - Universidade Estadual Paulista, 1998.

MILLER, L., QURESHI, M.A. 1992a. Induction of heat-shock proteins and phagocytic function of chicken macrophage following in vitro heat exposure. Vet. Immunol. Immunopathol., 30(1):179-191.

MILLER, L., QURESHI, M.A. 1992b. Heat-shock protein synthesis in chicken macrophages: influence in vivo and in vitro heat shock, lead acetate and lipopolysaccharide. Poult. Sci., 71(6):988-998.

MORIMOTO, R.I., FODOR, E. 1984. Cell-specific expression of heat shock proteins in chicken reticulocytes and lymphocytes. J. Cell. Biol., 99(6):1316-1323.

MORIMOTO, R.I., HUNT, C., HUANG, S.Y. et al. 1986. Organization, nucleotide sequences, and transcription of chicken Hsp70 gene. J. Biol. Chem., 261(27):12692-12699.

MORRISSEY, D.H. 1981. Silver strain for proteins in polyacrilamide gels: a modified procedure with enhanced uniform sensitivity. Anal. Biochem., 117(2):307-310.

PARSELL, D.A., LINDQUIST, S. 1995. Heat shock proteins and stress tolerance. In: The biology of heat shock proteins and molecular chaperones. Cold Spring Harbor: Cold Spring Harbor Laboratory Press. p.457-495.

SAMBROOK, J., FRITSCH, E.F., MANIATIS, T. 1989. 
Molecular cloning: a laboratory manual. 2.ed. Cold Spring Harbor, Cold Spring Harbor Laboratory Press.

SCHMIDT-NIELSEN, K. 1995. Animal physiology: adaptation and environment. New York, Cambridge, University Press. p.241-293.

SKIDMORE, R., GUTIERREZ, J.A., GUERRIERO, V.JR. et al. 1995. Hsp70 induction during exercise and heat stress in rats: role of internal temperature. Am. J. Physiol., 268(1):R92-R97.

SOUTHERN, E.M. 1975. Detection of specific sequences among DNA fragments separated by gel electrophoresis. J. Mol. Biol., 98(4):503-517.

THEODORAKIS, N.G., BANERJI, S.S., MORIMOTO, R.I. 1988. Hsp70 RNA messenger translations in chicken reticulocytes is regulated at the level of elongation. J. Biol. Chem., 263(29):14579-14585.

TOWBIN, H., STAELIN, T., GORDON, J. 1979. Electrophoretic transfer of proteins from polyacrylamide gels to nitrocellulose sheets: procedure and some applications. Proc. Nat. Acad. Sci. USA, 76(9):4350-4354.
WANG, S., EDENS, F.W. 1993. Stress-induced heat shock protein synthesis in peripheral leukocytes of turkeys, Meleagris gallopavo. Comp. Biochem. Physiol., 106b(3):621-628.

WANG, S., EDENS, F.W. 1994. Hsp70 RNA messenger expression in heat-stressed chicken. Comp. Biochem. Physiol., 107b(1):33-37.

YAHAV, S., SHAMAY, A., HOREV, G. et al. 1997. Effect of acquisition of improved thermotolerance on the induction of heat shock protein in broiler chickens. Poult. Sci., 76(10):1428-1434.

YAHAV, S., LUGER, D., CAHANER, A. et al. 1998. Thermoregulation in naked neck chickens subjected to different ambient temperatures. Br. Poult. Sci., 39(1):133-138.

Recebido em:06/09/00

Aceito em: 15/05/01 